\title{
Concepções dos docentes sobre sexualidade em turmas dos anos finais, em uma escola no município de Governador Mangabeira-BA
}

\section{The teacher conceptions about final sexuality in classes in a school from}

\section{Governador Mangabeira-BA}

\author{
Caliandre Almeida Gonçalves ${ }^{1}$; Joana Gomes dos Santos Figuereido ${ }^{2}$ \\ ${ }^{1}$ Faculdade Maria Milza - Famam; Governador Mangabeira-BA; Bahia, Brasil. E-mail: \\ kaly_1515@hotmail.com \\ ${ }^{2}$ Universidade Estadual de Feira de Santana - UEFS; Feira de Santana-BA; Bahia, Brasil. \\ E-mail: joanagsf@gmail.com
}

\section{Resumo}

A sexualidade é constituída de aspectos físicos, psicológicos, históricos e socioculturais. Ela está presente na vida dos jovens, trazendo-lhes questionamentos, dúvidas e incertezas. Por isso, entende-se a relevância do papel da escola ao trabalhar questões relacionadas à sexualidade, já que a escola deve ajudar o discente a sanar suas dúvidas, fortalecendo seu desenvolvimento crítico e social. Mais relevante ainda é o papel do docente, que deve preparar-se para levar para sala de aula diálogos e reflexões acerca desta temática. Nesse sentido, o objetivo geral desta pesquisa é conhecer as concepções dos professores em turmas do Ensino Fundamental dos Anos Finais, em uma escola no município de Governador Mangabeira-BA. A metodologia utilizada foi de natureza qualitativa, procurando compreender o caráter subjetivo do objeto em questão, usando o método investigativo descritivo. Quanto ao delineamento, foi uma pesquisa de campo, realizado em uma escola de Ensino Fundamental II, no município de Governador Mangabeira- BA. Como instrumento de coleta de dados aplicou-se questionários aos professores que lecionam nas turmas dos anos finais. Os resultados mostram que a maioria dos docentes possui uma concepção equivocada sobre sexualidade e necessitam de uma formação específica, seja ela inicial ou continuada.

Palavras-chave: Sexualidade. Concepções docentes. Documentos oficiais educacionais.

\begin{abstract}
Sexuality consists of physical, psychological, historical and socio-cultural aspects. It is present in the lives of young people, bringing those questions, doubts and uncertainties.
\end{abstract}


Therefore, it is understood the relevance of the school's role when working on issues related to sexuality, since the school must help the student to solve their doubts, strengthening their critical and social development. Even more relevant is the role of the teacher, who must be prepared to take dialogues and reflections on this theme to the classroom. In this sense, the general objective of this research is to know the teachers' conceptions in classes of the Elementary School of the Final Years, in a school in the city of Governador MangabeiraBA. The methodology used was of a qualitative nature, trying to understand the subjective character of the object in question, using the descriptive investigative method. As for the design, it was a field research, carried out in an elementary school II, in the city of Governador Mangabeira-BA. As a data collection instrument, questionnaires were applied to teachers who teach in the classes of the final years. The results show that the majority of teachers have a mistaken conception of sexuality and need specific training, whether initial or continuing.

Keywords: Sexuality. Teachingconceptions. Educationalofficialdocuments.

\section{Introdução}

A sexualidade está presente em todos os âmbitos da vida dos seres humanos, em todo seu desenvolvimento físico e psicológico, desde que nascem até a morte. Em momento nenhum as pessoas encontram-se isentos da sexualidade, pois ela abrange não somente aspectos biológicos, mas também histórico-culturais (COSTA; OLIVEIRA, 2011).

Falar sobre questões relacionadas ao sexo e à sexualidade, desde tempos antigos, é um grande tabu. Apesar de todo o avanço na civilização, o sexo em si ainda é carregado de preconceitos. A desconstrução de preconceitos e a formação de conceitos devem ser apresentadas aos indivíduos desde a mais tenra idade, e principalmente no período da adolescência, que é uma fase de transição e de construção do "si", com as incertezas, crises e conflitos características da passagem para a vida adulta. É o período em que o jovem desenvolverá sua identidade, para determinar o seu "eu" no futuro. E é exatamente nessa fase que a sexualidade deve ser discutida, para que seja entendida de forma correta e para que os alunos aprendam a lidar com ela (MOIZÉS; BUENO, 2010).

Sempre se ouve falar que a educação vem de casa, porém a educação familiar, apesar de ser fundamental sozinha não é suficiente para a formação integral do ser humano, pois em muitas famílias questões sexuais são omitidas por diversos motivos religiosos e sociais. (JARDIM; BRÊTAS, 2006).

Portanto, a escola é o espaço ideal para se tratar temas específicos, como os ligados à 
sexualidade, possibilitando, assim, através da convivência, a aquisição de diferentes aprendizagens que favorecem a socialização e internalização de novas crenças, comportamentos, novas formas de se relacionar, como também o conhecimento de outras culturas e experiências em torno de diferentes aspectos relacionados à sexualidade. (BRASIL, 2018).

Diante desses pressupostos, o presente trabalho traz como questionamento: "Quais as concepções docentes sobre as questões da sexualidade em turmas dos Anos Finais, em uma escola no município de Governador Mangabeira-BA?" Partindo deste questionamento, este estudo tem como objetivo geral conhecer as concepções dos professores, em turmas dos Anos Finais, numa escola no município de Governador Mangabeira, acerca das questões da sexualidade no espaço escolar, evidenciando, assim, a importância de se discutir sobre a sexualidade, principalmente na escola, pois esta instituição tem como uma das funções formar sujeitos conscientes e ativos na sociedade.

\section{Materiais e Métodos}

A fim de se estabelecer a relação entre o contexto do desenvolvimento desse estudo e os objetivos propostos, realizou-se um estudo descritivo. Segundo Andrade (2005), nesse tipo de estudo, os fatos são observados, registrados, analisados, classificados e interpretados sem que o pesquisador interfira neles, significando, assim, que os fenômenos do mundo físico e humano são estudados, mas não manipulados pelo pesquisador (TRIVIÑOS, 1987).

Quanto à abordagem, essa pesquisa possui natureza qualitativa, pois procura compreender o caráter subjetivo do objeto em questão, não se preocupando com a representatividade numérica. Para Minayo (2001), a pesquisa qualitativa trabalha com o universo de significados, motivos, aspirações, crenças, valores e atitudes, o que corresponde a um espaço mais profundo das relações, dos processos e dos fenômenos que não podem ser reduzidos à operacionalização de variáveis.

Essa pesquisa constitui-se também como pesquisa de campo, pois se caracteriza pela coleta de dados junto a pessoas e em um determinado ambiente, utilizando-se de técnicas específicas, as quais têm o objetivo de recolher e registrar, de maneira ordenada, os dados sobre o assunto em estudo (ANDRADE, 2005). Como técnicas de coleta de dados em busca 
do alcance dos objetivos específicos traçados, foram aplicados questionários aos onze professores das turmas Anos Finais ( $8^{\circ}$ e $9^{\circ}$ anos) em uma escola no município de Governador Mangabeira-BA. Segundo Gerhardt e Silveira (2009), o questionário é um instrumento de coleta de dados constituído por uma série ordenada de perguntas que devem ser respondidas por escrito pelo informante, sem a presença do pesquisador, objetivando levantar opiniões, crenças, sentimentos, interesses, expectativas e situações vivenciadas. A linguagem utilizada no questionário deve ser simples e direta, para que quem responda compreenda com clareza o que está sendo perguntado.

Posteriormente, foi realizada uma análise textual discursiva, após coletar todas as informações necessárias para a análise da pesquisa. Essa análise textual apresentou não somente os dados, mas também colocações críticas sobre eles, tendo como base a revisão de literatura apresentada anteriormente.

\section{Resultados e Discussão}

\subsection{Lócus da pesquisa, observações no contexto escolar e perfil dos professores entrevistados}

As atividades de aplicação de questionário foram realizadas com os docentes das turmas do $8^{\circ}$ e $9^{\circ}$ ano, em uma escola situada no município de Governador Mangabeira no Estado da Bahia, localizada na zona urbana, para atender alunos da Educação Infantil ao Ensino Médio. O bom número de funcionários, o bom espaço físico, e o vínculo com a comunidade externa e pais facilitam o desenvolvimento do trabalho de ensino-aprendizagem das crianças. Os questionários foram aplicados com professores das turmas do $8^{\circ}$ e $9^{\circ}$ anos, os quais foram nomeados como P1, P2, P3, P4, P5, P6, P7, P8, P9, P10 e P1 - nomes fictícios dados a eles a fim de preservar suas verdadeiras identidades, por princípio ético.

As turmas funcionam no turno matutino com 23 alunos na turma do $8^{\circ}$ ano, e 14 alunos na turma do $9^{\circ}$ ano. O número de professores, conjuntamente nas duas turmas, é 15. As salas são amplas e, ao todo, a escola possui 16 salas de aulas, uma biblioteca, uma sala de informática, uma sala de vídeo, um auditório, banheiros femininos e masculinos, quadra e área verde. Diversos funcionários, entre agente de portaria, serviços gerais, merendeiras, 
auxiliares de salas, diretor, coordenadora pedagógica, secretárias e um total de 28 professores em toda Instituição.

No quadro 01, saoapresetadas as informações sobre o perfil dos professores que particpiram da pesquisa.

Quadro 01- Perfil dos professores pesquisados

\begin{tabular}{|c|c|c|c|c|c|c|c|}
\hline $\begin{array}{l}\text { Entrevistad } \\
\text { os }\end{array}$ & $\begin{array}{c}\text { Gêner } \\
\text { o }\end{array}$ & Idade & E.P.D. & $\begin{array}{c}\text { Ano de } \\
\text { formação }\end{array}$ & $\begin{array}{c}\text { Área de } \\
\text { formação }\end{array}$ & $\begin{array}{c}\text { Disciplina } \\
\text { de atuação }\end{array}$ & Religião \\
\hline P1 & $\mathrm{M}$ & $\begin{array}{c}30 \\
\text { anos }\end{array}$ & $\leq 1$ ano & - & $\begin{array}{l}\text { Geografia, } \\
\text { História }\end{array}$ & Geografia & Nenhuma \\
\hline P2 & $\mathrm{F}$ & $\begin{array}{c}33 \\
\text { anos }\end{array}$ & 7 anos & 2000 & Letras & Espanhol & $\begin{array}{c}\text { Adventist } \\
\text { a do } 7^{\circ} \\
\text { Dia }\end{array}$ \\
\hline P3 & $\mathrm{F}$ & $\begin{array}{c}43 \\
\text { anos }\end{array}$ & 9 anos & 2012 & $\begin{array}{l}\text { Licenciatura em } \\
\text { Educação Física }\end{array}$ & $\begin{array}{l}\text { Educação } \\
\text { Física }\end{array}$ & - \\
\hline P4 & $\mathrm{F}$ & $\begin{array}{c}51 \\
\text { anos }\end{array}$ & $\begin{array}{c}31 \\
\text { anos }\end{array}$ & 2014 & $\begin{array}{l}\text { Pedagogia- } \\
\text { Especialização } \\
\text { em Artes }\end{array}$ & Artes & Católica \\
\hline P5 & M & $\begin{array}{c}39 \\
\text { anos }\end{array}$ & $\begin{array}{c}17 \\
\text { anos }\end{array}$ & 2014 & Matemática & Matemática & Católico \\
\hline P6 & $\mathrm{F}$ & $\begin{array}{c}34 \\
\text { anos }\end{array}$ & 3 anos & 2018 & $\begin{array}{c}\text { Mestre em } \\
\text { Recursos } \\
\text { Genéticos } \\
\text { Vegetais }\end{array}$ & Ciências & - \\
\hline P7 & M & $\begin{array}{c}30 \\
\text { anos }\end{array}$ & 8 anos & 2014 & $\begin{array}{l}\text { Bacharelado em } \\
\text { Ciências Exatas }\end{array}$ & Matemática & Católico \\
\hline P8 & $\mathrm{F}$ & $\begin{array}{c}29 \\
\text { anos }\end{array}$ & 9 anos & 2014 & $\begin{array}{c}\text { Licenciatura em } \\
\text { História }\end{array}$ & História & Espírita \\
\hline P9 & $\mathrm{F}$ & $\begin{array}{l}35 \\
\text { anos }\end{array}$ & $\begin{array}{c}12 \\
\text { anos }\end{array}$ & 2008 & $\begin{array}{c}\text { Licenciatura em } \\
\text { História }\end{array}$ & História & - \\
\hline P10 & $\mathrm{F}$ & $\begin{array}{c}27 \\
\text { anos }\end{array}$ & 6 anos & 2013 & Letras Vernáculas & $\begin{array}{l}\text { Português/ } \\
\text { Redação }\end{array}$ & Católica \\
\hline P11 & $\mathrm{F}$ & $\begin{array}{c}32 \\
\text { anos }\end{array}$ & 1 ano & 2016 & $\begin{array}{c}\text { Comunicação } \\
\text { Social }\end{array}$ & Inglês & Gnóstica \\
\hline
\end{tabular}

EPD: Experiência profissional da docência; (-) não quis responder.

Nota-se que os professores possuem formação acadêmica e experiência na educação, porém percebe-se nas considerações posteriores que, apesar de muitos possuírem nível superior e anos de experiência, a temática da sexualidade ainda é desconhecida para alguns deles. Isso pode ser supostamente explicado pelo número de professores que aceitaram responder ao questionário, em um total de 15 professores das turmas do $8^{\circ}$ e $9^{\circ}$ ano, apenas 11 responderam os demais se recusaram a respondê-lo.

O professor muitas vezes sente insegurança para tratar dos assuntos referentes à 
sexualidade dos seus alunos: "A vergonha que os professores têm a falar sobre sexo dificulta a educação sexual. [...] Os professores só estão preparados para as disciplinas específicas e fogem do assunto sexo" (SILVA, 1997, p. 217). Esquecendo que a sexualidade, não trata do “sexo" por si só, além disso, possui outras abrangências.

\subsection{Sexualidade no espaço escolar}

Falar sobre sexo é um grande tabu, principalmente no ambiente familiar e religioso. $\mathrm{Na}$ escola não é diferente. Os docentes evitam se aprofundar nessas questões e tratam esse assunto apenas nas aulas de ciências de forma superficial. Mesmo sabendo que a educação familiar é uma das mais importantes para o ser humano, é a escola o espaço ideal para que crianças e adolescentes possam fazer seus questionamentos, sendo responsabilidade do sistema escolar promover a educação integral da criança e do adolescente e, portanto, trazer discussões sobre a sexualidade, promovendo a Educação Sexual.

Segundo Almeida e Assis (2010), a sexualidade tem grande destaque na sociedade, já que a mídia, a internet, as revistas, as músicas apresentam com bastante frequência esse tema tão pensado pelos jovens. A mídia constantemente propaga a sexualidade em torno do sexo e erotismo, desencadeando, assim, a precocidade da iniciação sexual, assim como sua banalização. Porém falar sobre sexualidade vai além de discussões sobre o sexo e como é feito. É esclarecer dúvidas e questionamentos associados às questões do prazer, das escolhas e liberdades individuais e a conscientização do sexo livre sem preconceito.

As escolas devem promover um trabalho "mais amplo, utilizando a multi, a inter e a transdisciplinaridade, considerando as dimensões biológica, psicológica, social, contribuindo para o fortalecimento da autoestima e da identidade pessoal" (MÓIZES; BUENO, 2010). Levando, assim, ao reconhecimento da Educação Sexual no cotidiano escolar, enquanto um agente provedor de educação.

Para que discussão sobre essa temática no espaço escolar ocorra de forma eficiente, pode-se recorrer a várias estratégias de ensino, as quais devem estar ancoradas em princípios que levem em consideração que a sexualidade não se resume a ensinar os conteúdos de biologia e fisiologia humana, mas que tal ensino oportunize aos alunos expressarem seus 
sentimentos, inquietudes e dúvidas, refletindo sobre suas atitudes e revendo preconceitos e conceitos. Ou seja, o professor deve considerar o educando como sujeito ativo no processo ensino-aprendizagem, abrindo espaço para o aluno falar e ouvir seus colegas, criando as condições para o aluno aprender, ao invés de ser um simples transmissor de conhecimentos.

Deste modo, o desenvolvimento do trabalho da educação sexual nas escolas, segundo Furlani (2009), tem como objetivo fundamental contribuir para que os alunos e alunas possam viver suas sexualidades de forma mais emancipatória, mais prazerosa, mais afetiva. Esse tema vincula-se ao exercício da cidadania na medida em que se propõe a trabalhar o respeito por si e pelo outro, ao mesmo tempo busca garantir direitos básicos a todos, como a saúde, a informação e o conhecimento, elementos fundamentais para a formação de cidadãos responsáveis e conscientes de suas capacidades, de seus direitos, de seus deveres.

\subsection{Processo de formação dos professores sobre a sexualidade}

É relevante que ocorra o processo de formação de professores em torno das questões da sexualidade, pois, com tal formação, os docentes podem assumir o seu papel fundamental no processo de educação sexual da criança e do adolescente, vindo teoricamente a compreender as manifestações da sexualidade dos alunos, educando-os para uma sexualidade liberta, consciente e humanista.

O primeiro passo para o docente discutir sobre questões sexuais em sala de aula é compreender o educando como sujeito de direitos; entender também que as questões referentes a sexualidade transcorrem a instituição escolar, sendo assim uma característica essencialmente humana. Logo, faz-se necessário que o docente possua formação para o desenvolvimento de trabalhos voltados à sexualidade. Esses trabalhos devem ser realizados através da educação sexual, a qual, para Figueiró (2006), é um processo contínuo e ocorre através dos valores e conceitos sobre sexo e sexualidade, transmitidos nos espaços familiares, nos meios de comunicação de massa, como também na escola.

A formação do docente deve percorrer por diversas vertentes e áreas, inclusive pelo estudo de temas de relevância social, como a sexualidade. No que tange aos cursos de formação de professores, pode-se notar no documento da Resolução do Conselho Nacional 
de Educação, no artigo $5^{\circ}$, umas das competências essenciais aos egressos dos cursos de Pedagogia é "demonstrar consciência da diversidade, respeitando as diferenças de natureza ambiental-ecológica, étnico-racial, de gêneros, faixas geracionais, classes sociais, religiões, necessidade especiais, escolhas sexuais, entre outras" (BRASIL, 2006, p.2).

O artigo da Resolução do Conselho Nacional de Educação, como é retratado acima, afirma que o professor deve terminar do curso tendo consciência de fatores importantes como diversidade, o respeito ao gênero e as escolhas sexuais, porém, na prática docente, não se observa tal consciência e respeito, e sim ocultação e silenciamento desses aspectos, já que muitos professores não conseguem falar abertamente sobre essas questões da sexualidade. Segundo Guimarães (1995), uma preparação especializada dos professores auxiliaria na redução desse receio de falar de sexo em sala de aula, mas não somente do sexo e sim de todas as questões que a sexualidade abarca.

Para isso, entretanto, há necessidade da ajuda e reconhecimento de políticas públicas educacionais sobre a abordagem da sexualidade, não só na formação inicial dos professores, mas também continuada, para implantá-la nas práticas escolares cotidianas da educação formal. Portanto, o educador deve obter capacitação sobre esse tema relevante, para que possa despir-se dos seus preconceitos e tabus, assumindo o importante papel de transmissor e formador, abordando diversas questões teóricas/práticas, leituras e discussões sobre o tema, atendendo suas peculiaridades e generalidades. Vindo sempre a provocar nos alunos reflexões e conscientização, para que eliminem preconceitos e busque primeiramente sua felicidade em viver sua sexualidade livremente.

\subsection{Concepções dos professores sobre sexualidade}

A fim de se obter uma compreensão plausível sobre a concepção dos professores em torno da sexualidade, buscou-se por meio de questionamentos e respostas aprofundar-se em torno do objeto de estudo, um aprofundamento da temática, entendendo quais conhecimentos os professores possuem sobre sexualidade e se em sua prática na sala de aula abordam-na.

Primeiramente, interessou-se em saber o que os professores que responderam ao 
questionário entendiam sobre o conceito de sexualidade e se os mesmos já vivenciaram alguma situação ou possuem dificuldades de falar sobre o tema (Quadro 02).

Quadro 02 - Respostas atribuídas quanto ao conceito de sexualidade.

P1: "Um conjunto de características internas e externas de um indivíduo, determinadas pelo nascimento juntamente com o comportamento que esse indivíduo tem frente essas características".

P2: "Conjunto de comportamento do ser humano, em torno da realização ou necessidade sexual".

P3: "Conjunto de sentimentos, afetos, sensações prazerosas, e não somente o sexo em si".

P4: "São traços ou podemos dizer características. São sensações e sentimentos individuais que nos permite ter relações diferentes com as pessoas. Porém muitas vezes, só associado ao sexo".

P5: "É o despertar para o namoro, fato que acontece na adolescência com a chegada da puberdade".

P6: "É um termo bastante amplo que pode ser englobado em vários conceitos, desde fatores relacionados em desenvolvimento entre as espécies até a dinâmica do próprio corpo".

P7: "Em resumo, sexualidade é o desejo afetivo por outro ser humano, seja do mesmo sexo ou não".

P8: "É o entendimento dos nossos sentimentos e atitudes desenvolvidas a partir de situações internas e externas sobre o nosso corpo".

P9: "Características internas e externas que definem a personalidade de um indivíduo".

P10: "Envolve as escolhas e as vontades que um indivíduo tem".

P11: "A forma como o indivíduo percebe o desejo sexual".

As respostas dadas pelos professores demonstram o nível de conhecimento que possuem sobre o que é sexualidade, percebendo-se, assim, que há um entendimento sobre a temática, ainda que superficial. Não há uma única definição de sexualidade, o termo traz um conceito diverso, que abrange os variados comportamentos do ser humano em si e isso fica expresso nas respostas dos professores que apontam aspectos diversos relacionados à temática.

Pode-se perceber que o entendimento sobre o que é sexualidade para esse professores, mesmo que limitado, está relacionado ao conceito da Organização Mundial de Saúde (PONTES 2011, p. 23), que define a "sexualidade como um aspecto central do ser humano ao longo da vida (...). A sexualidade é experiência e se expressa através de pensamentos, fantasias, desejos, crenças, atitudes, valores, comportamentos, práticas, papéis e relações".

Com base nesse conceito da sexualidade, P2, P5, P7 e P11 deixaram explícito que não possuem compreensão ampla sobre essa temática, quando alegam que a sexualidade está 
relacionada somente ao sexo, "desejo sexual, "realização ou necessidade sexual". Isso acontece quando não há uma formação adequada para os professores sobre o assunto.

Segundo Desidério (2013), a sexualidade não se reduz apenas às questões biológicas e tampouco pode ser confundida com o ato sexual reprodutivo, porém os professores carregam consigo conceitos equivocados, ao acreditam que a sexualidade está apenas relacionada ao sexo e à relação sexual, esquecendo tantos outros aspectos relevantes sobre a temática. Quando os entrevistados foram questionados sobre a importância das discussões sobre a sexualidade no espaço escolar, foram obtidas as seguintes respostas (Quadro 03).

Quadro 03- A importância de se discutir a sexualidade no espaço escolar.

P1: "Penso ser mais apropriado no espaço familiar, contudo, a escola seria um segundo espaço propício a esse tipo de discussão".

P2: “Sim. A escola precisa tratar sobre alguns temas importantes do cotidiano'.

P3: "Sim. As instituições escolares devem discutir sobre a sexualidade, focalizando na formação em valores, com respeito ao outro e a si mesmo".

P4: "Sim, por ser a escola um espaço importante e de forte referência na vida de todos".

P5: "Sim, pois com esse tema sendo discutido poderá haver uma prevenção da gravidez na adolescência e também nas doenças sexualmente transmissíveis".

P6: "Sim, pois, é um local de maior disseminação e discussão do conhecimento cientifico".

P7: "Sim, porque faz parte da formação humana, que deve ser construída no ambiente escolar, mas também no familiar".

P8: "Sim. A escola é um espaço de formação cidadã, onde muitos dos indivíduos que a constituem, não possuem a oportunidade de conversar sobre o assunto em casa. E é nesse espaço que os alunos podem ter conhecimento sobre o assunto de forma segura e responsável, bem diferente das rodas de conversas entre amigos".

P9: "Com certeza. Por ser a escola lugar de formação social crítica e reflexiva, atenta as diferenças".

P10: "Sim, porque é necessário o conhecimento para que o respeito as diferenças existam".

P11: "Sim, por ser um ambiente social e de aprendizado, e no qual muitas vezes o indivíduo se sente mais à vontade pra discussão do assunto, podendo servir também como ponte de diálogo sobre o tema entre pais e filhos".

Todos os professores afirmaram que concordam que a sexualidade deve ser discutida no espaço escolar, ressaltando sua relevância, “[...] incumbindo à escola abordar os mais 
diversos pontos de vista, valores e crenças existentes na sociedade, visando auxiliar o aluno a construir em si, uma autorreferência por meio da reflexão" (BRASIL, 1997, p.83). Podese perceber que a resposta de P3 corrobora o que Brasil (1997) fala: "Sim. As instituições escolares devem discutir sobre a sexualidade, focalizando na formação em valores, com respeito ao outro e a si mesmo".

Os jovens vivenciam diversas situações cotidianas, as quais estão diretamente relacionadas à sexualidade, havendo, pois, a necessidade de discuti-la nos espaços escolares, promovendo reflexão, formação de saberes e valores, oportunizando aos jovens autoconhecimentos para que saibam lidar de forma madura em todas as situações de suas vidas. Segundo Figueiredo (2000), é fundamental, na escola, a oferta de um espaço onde as crianças e adolescentes possam esclarecer suas dúvidas e continuar formulando novas questões sobre sexualidade. Isto contribui para o alivio de ansiedades e tensões que, muitas vezes, interferem no aprendizado dos conteúdos escolares.

Moizés e Bueno (2010) corroboram Figuereido (2010) ao defenderem a escola como espaço privilegiado para que crianças e adolescentes possam fazer seus questionamentos. É na escola que as crianças podem compreender melhor a sexualidade em seu sentido mais amplo, superando equívocos e dúvidas que não conseguem esclarecer em outros espaços, como em casa, por exemplo, já que, como já discutido acima, essa temática está envolta de tabus.

Outra resposta bastante interessante foi apresentada por P5, ao dizer que se na escola esse tema for discutido, poderá haver uma prevenção da gravidez na adolescência e de infecções sexualmente transmissíveis (ISTs). Entretanto, é importante lembrar que discutir sobre sexualidade não se trata apenas disso, vai muito além da discussão sobre relações sexuais e formas de prevenção, trata-se de refletir modos de relacionamento com o outro, identidades, vidas, sentimentos, dentre tantas outras coisas.

No questionamento seguinte, observam-se as respostas que os professores deram quando perguntados sobre quais são as dificuldades, limitações e desafios para trabalhar a sexualidade em sala de aula. O quatro 04 , a seguir, traz as seguintes respostas:

Quadro 04- Dificuldades pessoais e desafios para trabalhar sexualidade na sala de aula. 
P1: "Não tenho dificuldade. E um dos maiores desafios é o fato de ser um assunto que trata da intimidade, e assim, não ser abertamente falado na sociedade".

P2: "Tenho um pouco de dificuldade sim, principalmente para trabalhar nas turmas dos anos finais".

P3: "Tenho um pouco de dificuldade. E um dos desafios na minha concepção, é que meninas ainda sentem vergonha de discutir sobre o assunto, enquanto alguns meninos levam o assunto muito na brincadeira".

P4: "Não tenho dificuldade. É muito tranquilo quando surgem algumas questões. Na sala de aula o maior desafio, é buscar falar de forma tão simples para que não chegue em casa a informação que o professor estar entrando onde não deve".

P5: "Sim possuo dificuldade. As crianças e adolescentes, estão descobrindo a sexualidade e os limites do próprio corpo. Considerando ainda, que hoje em dia, eles parecem saber muito sobre sexo, contudo, muitas vezes recebem informações incompletas e acompanhadas de uma visão obscena a respeito apenas do sexo".

P6: "Tenho. Até o momento a única dificuldade encontrada é a falta de materiais que possam contribuir ainda mais com as aulas, pois ainda existe um certo "tabu" com essa questão (conteúdo), quando o mesmo é ensinado em sala de aula".

P7: "Tenho. A maior dificuldade é a velocidade da evolução dos diferentes tipos de sexualidade. É como "pisar em ovos". Quando não se deseja ferir os sentimentos de alguém, todo cuidado nas falas é pouco".

P8: "Sim. Além dos risos tímidos dos alunos, que aparentam ser sinônimo de constrangimento quando esse assunto é discutido, há a reação negativa de alguns responsáveis, a respeito do assunto discutido em sala. Já que muitos acham que sexualidade está diretamente relacionada com o sexo, que para nossa sociedade ainda é visto como uma coisa proibida e suja".

P9: "Não tenho dificuldades até por conta da minha formação pessoal e acadêmica. Entretanto, tenho muito cuidado ao trabalhar essa temática, pois a mesma está atrelada a muitos tabus.

P10: "Tenho. Devido a formação religiosa e timidez, o tema "sexo" ou "sexualidade" ainda é tabu. Além disso, há toda uma preocupação da família, além da maturidade dos alunos".

P11: "Não. Mesmo sendo um assunto do qual trato com neutralidade, sempre há limitações provenientes do ambiente familiar ou da sociedade. Umas das maiores dificuldades de trabalhar o tema é a desconstrução de pensamentos e comportamentos pré-estabelecidos".

A maioria dos professores, P2, P3, P5, P6, P8, P9, P10, possui limitações pessoais e dificuldades em falar sobre o tema em sala de aula, enquanto os demais, P1, P4, P9 e P11, afirmam que não possuem limitações ou dificuldades. Através das respostas apresentadas no questionário, observam-se vários motivos que levam os docentes a não realizarem as discussões dessa temática com os alunos.

Dentre os motivos, sinalizam vergonha e receio da reação dos alunos e da comunidade escolar como um todo, já que, como já expresso em outras respostas, o tabu imposto pela sociedade brasileira, conservadora e pouco informada, em torno da temática sexualidade ainda é muito grande. Junto a esses dois fatores, como também já apontoado pelos professores, a preocupação em desagradar os pais que julgam de forma preconceituosa atividades vinculadas a assuntos tabus.

Neste sentido entende-se que os professores são receosos sobre as reações dos pais ao 
sabem que a temática sexualidade está sendo discutida em sala de aula. Muitos pais, equivocadamente, ainda entendem a discussão sobre sexualidade como apenas discutir sexo ou veem tal discussão como um estímulo à iniciação da vida sexual dos jovens. Por isso, segundo Werebe (1998), nem sempre os pais oferecem aos filhos informações sobre a sexualidade, seja porque não possuem os conhecimentos para fazê-lo, seja porque se sentem constrangidos para tratar do assunto.

Soma-se a isso ainda, a falta de recursos didático-pedagógicos disponíveis nas escolas que possam facilitar a realização de atividades que dinamizem o assunto nas aulas, tornando assim o processo mais dificultoso ainda.

Segundo Brêtas e Jardim (2006), ainda existe entre os educadores a concepção que se falarem sobre determinados assuntos estarão estimulando a sua prática, quando na realidade os adolescentes muitas vezes já têm conhecimento desses "tabus" e carecem de esclarecimentos. Logo, se os educadores ficarem reféns aos tabus impregnados, não vão transmitir em suas práticas a discussão relevante desse tema.

Em seguida, foi analisada a opinião dos professores em relação à relevância que dão ao processo de formação inicial e/ou continuada dos docentes sobre a sexualidade e se eles possuem tal formação. Observam-se tais opiniões expressas no quadro 05, abaixo:

Quadro 05- Relevância da formação inicial e/ou continuada dos professores sobre sexualidade

P1: "Eu acho relevante somente caso a escola venha a trabalhar essa questão, e principalmente para os professores de ciências biológicas."

P2: "Sim. Precisamos estar atualizados a cada dia".

P3: "Sim, porque é essencial que o professor tenha uma visão positiva do corpo, da relação sexual, do relacionamento com o outro, da concepção sobre a diversidade sexual, de tudo que envolva a sexualidade, para assim pode falar e trabalhar com naturalidade sobre assunto".

P4: "Sim, pois nós professores temos que estar sempre preparados para lidar com as mais diversas situações".

P5: "Sim, pois facilita para o professor discutir sobre o assunto em sala de aula, caso haja necessidade".

P6: "Acredito que não seja uma questão fundamental para a formação docente, entretanto iria contribuir ainda mais no conhecimento do profissional".

P7: "Sim. Toda e qualquer formação continuada é de extrema relevância para qualquer segmento/profissão. O acúmulo de conhecimento científico e humano alicerça a evolução". 
P8: "Não acho que seja necessariamente relevante. Porém, caso o profissional queira estar por dentro do assunto, acho importante, pois estamos sempre por dentro das discussões de gênero, da valorização e de modos de vida, etc".

P9: "Sim, pois é algo que faz parte para a formação integral do aluno, e que muitos professores não sabem lidar".

P10: "Sim. Para conseguir abordar o assunto com confiança, além disso, para estimular o conhecimento dos educandos".

P11: "Sim, pela escola ser um ambiente de formação social e intelectual, questões sobre sexualidade são recorrentes, logo é preciso que nós como professores saibam lidar e trabalhar o assunto em ambiente escolar de forma adequada".

O papel da profissão docente está inserido em um contexto social e político e sua formação, seja ela inicial ou continuada, influenciará na formação e no processo de ensinoaprendizagem dos alunos. Carvalho (2004, p. 28) considera que a "[...] formação docente inicial e continuada deve ampliar os espaços de reflexão sobre a ação docente e empoderar/instrumentar educadoras e educadores para o desafio da reflexão na ação". Desta forma, a formação docente é extremamente importante para apropriação do professor sobre o tema sexualidade, possibilitando uma melhor compreensão em torno das questões que circundam a temática, para vir a dar os encaminhamentos possíveis e necessários no decorrer do processo educativo nas práticas voltas à sexualidade.

Isso fica evidenciado na maioria das respostas apresentadas acima pelos docentes, ao considerarem que a formação voltada à sexualidade trará conhecimento científico para embasar as aulas, permitindo não apenas o acesso a mais informações, mas também descontruindo preconceitos e criando consciência da importância das discussões sobre o assunto em sala de aula.

Segundo Batista (2008), os professores precisam se envolver num processo de crescimento, que requer comprometimento e esforço para que possam compartilhar reconhecer e identificar os obstáculos internos que os impedem de evoluir com relação à própria sexualidade para que, desse modo, possam percorrer um caminho no qual seus acompanhantes, os alunos, também evoluam e se descubram.

Houve um professor, P8, que afirmou que não considera relevante, nem importante a formação continuada em sexualidade, a não ser que o professor queira estar por dentro do assunto. Percebe-se aí um descaso a essa temática por esse professor. A concepção dele está 
errônea, pois a sexualidade merece atenção e deve ser trabalhada na escola.

Isso acontece porque "os cursos de formação de professores, na sua quase totalidade e por conta de uma tradição "familiar", carecem de discussão sobre este tema" (DESIDÉRIO, 2013, p.947). Desta forma, entende-se que todos os professores deviriam receber uma formação inicial acerca do assunto, pois, ao critério dos docentes, há o risco desta temática nunca ser mencionada em sala de aula.

Ainda foi perguntado aos professores se eles possuíam alguma formação inicial/continuada em sexualidade e se possuíam interesse em ter. Todos afirmaram que não possuíam nenhuma formação e a maioria ressaltou que não tem nenhum interesse em possuir. Nesta perspectiva, os discursos apresentados nas respostas dos professores mostram incongruências. Apesar dos professores reconhecerem a importância de se ter uma formação em sexualidade, os próprios não despertam o mínimo interesse em obtê-la. Nesse sentido, entende-se que a abordagem da sexualidade não é uma tarefa fácil para os profissionais da educação, pois ela se encontra envolta a valores morais e conservadores.

Diante dos pressupostos apresentados, verifica-se que há uma falha na formação inicial docente, não possuindo no currículo regular dos cursos de Graduação um espaço para a reflexão e discussão com os futuros professores sobre a sexualidade, e isso impossibilita a realização de um trabalho fundamentado, teórico e prático sobre esse tema no espaço escolar.

\section{Conclusões}

Diante o estudo realizado, constata-se que a sexualidade deve estar presente no contexto escolar e o educador deve prepara-se para lidar com essa questão, evitando considerar suas opiniões pessoais e reconhecendo sempre a importância de se falar sobre o assunto dentro das instituições, pois é um tema bastante presente na vida dos alunos, é um aspecto indissociável e que faz parte integral da formação humana.

Para isso, os educadores precisam de formação inicial e/ou continuada para obter informações a respeito do tema e lidar com ele de forma adequada, levando essas discussões para sala de aula. Desmunir-se de preconceitos e valores arraigados que os fazem ter 
concepções equivocadas, atrelando a sexualidade apenas ao sexo, ato sexual e reprodução, como se o trabalho com essa temática fosse voltado apenas à prevenção de ISTs e gravidez precoce. Assim, a escola deve criar consciência sobre a relevância dessas discussões e vir a proporcionar ao professor experiências em torno dessa temática através das formações.

Notou-se ainda que a maioria dos professores não possui formação específica em sexualidade e nem são preparados pelas escolas para sua discussão. Mas a maioria reconhece a importância dessas discussões no espaço escolar e admitem algumas dificuldades que impossibilitam essas discussões, como o tabu imposto pela sociedade, a falta de materiais didáticos, a incompreensão da família e até mesmo a falta de apoio das instituições onde ensinam.

Silenciando e banindo essas questões, a escola se torna um espaço cada vez mais conservador em que o saber sobre sexualidade e autoconhecimento são proibidos. O ideal a ser feito é incluir esse tema nos documentos oficiais, de forma transversal, para que as escolas venham obrigatoriamente a discuti-lo e, de forma autônoma, ajustá-lo as suas realidades escolares.

\section{Referências}

Almeida, A. P. E. \& assis, G. L. A. (2010). A sexualidade como construção social. CSOnline-Revista Eletrônica de Ciências Sociais, n. 4, v.10, p. 196-211

Andrade, M. M. (2005). Introdução à metodologia do trabalho científico: elaboração de trabalhos na graduação. 7.ed. São Paulo: Atlas, 176p.

Batista, C. A. (2008). Educação e sexualidade: um diálogo com educadores. São Paulo: Ícone, $148 \mathrm{p}$.

BRASIL, Ministério da Educação, (1997). Parâmetros Curriculares Nacionais para o Ensino Fundamental. Brasília, MEC/SEF.

BRASIL. Ministério da Educação e do Desporto. (2006). Conselho Nacional de Educação. Resolução CNE/CP n. 1, de 15 de maio de 2006. Institui Diretrizes Curriculares Nacionais para o Curso de Graduação em Pedagogia, licenciatura. p.1-11.

BRASIL. Secretaria de Educação Fundamental. (1997). Parâmetros Curriculares Nacionais: pluralidade cultural, orientação sexual. Secretaria de Educação Fundamental. - 
Brasília: MEC/SEF, 1997.

BRASIL. Ministério da Saúde. Secretaria de Atenção à Saúde. (2018). Departamento de Ações Programáticas e Estratégicas. Proteger e cuidar da saúde de adolescentes na atenção básica / Ministério da Saúde, Secretaria de Atenção à Saúde, Departamento de Ações Programáticas e Estratégicas. - 2. ed. - Brasília: Ministério da Saúde, 2018.

Costa, E. R. \& Oliveira, K. E. (2012). A sexualidade segundo a teoria psicanalítica freudiana e o papel dos pais neste processo. Itinerarius Reflectionis, v. 7, n. 1, p. 1-17. https://doi.org/10.5216/rir.v2i11.1239

Desidério, R. (2013). O que é sexualidade? Representações conceituais de professores sobre sexualidade em escolas paranaenses. Revista Ibero-Americana de Estudos em Educação, v. 8, n. 4, p. 945-960.

Figueiró, M. N. D. (2006). Formação de educadores sexuais: adiar não é mais possível. Campinas: Mercado de letras, 400p.

Furlani, J. (2009). Encarar o desafio da Educação Sexual na escola. In: Sexualidade; Secretaria de Estado da Educação. Superintendência de Educação. Departamento de Diversidades. Núcleo de Gênero e Diversidade Sexual. - Curitiba: SEED -Pr., 2009. - p. 37 -48 .

Gerhardt, T. E. \& Silveira, D. T. (2009). Métodos de pesquisa. Porto Alegre: Editora da UFRGS, 120p.

Gil, A. C. (2002). Como elaborar projetos de pesquisa. São Paulo: Atlas, 176p.

Guimarães, I. (1995). Educação sexual na escola: mito e realidade. Campinas-SP: Mercado das Letras, 128p.

Jardim, D. P. \& Brêtas, J. R. S. (2006). Orientação sexual na escola: a concepção dos professores de Jandira-SP. Revista da Escola de Enfermagem, v. 59, n. 2, p. 157-62.

Minayo, M. C. S. (2011). Pesquisa social: teoria, método e criatividade. Petrópolis: Vozes, $114 \mathrm{p}$.

Moizés, J. S. \& Bueno, S. M. V. (2010). Compreensão sobre sexualidade e sexo nas escolas segundo professores do ensino fundamental. Revista da Escola de Enfermagem, v. 44, n. 1, p. 205-212.

O.M.S. (2002). Growing in Confidence: Programming for Adolescent the health and Development - Lessons from eight countries. Department of Childand Adolescent Health 
and Development.

Silva, C. R. (1997). Possibilidades e limitações da escola pública como agente de educação sexual. In: Revista Brasileira de Sexualidade Humana., v.8, n.2,

Triviños, A. N. S. (1987). Introdução à pesquisa em ciências sociais, a pesquisa qualitativa em educação. São Paulo: Atlas, 176p.

Werebe, M. J. G. (1998). Sexualidade, Política, Educação. Campinas, SP: Autores Associados, 218p. 